\title{
Functional Starter Cultures for Meat: A Case Study on Technological and Probiotic Characterization
}

\author{
Antonio Bevilacqua*, Maria Rosaria Corbo, Barbara Speranza, Barbara Di Maggio, \\ Mariangela Gallo, Milena Sinigaglia \\ Department of the Science of Agriculture, Food and Environment, University of Foggia, \\ Foggia, Italy \\ Email: *antonio.bevilacqua@unifg.it, ${ }^{*}$ abevi@libero.it
}

Received 27 January 2015; accepted 5 April 2015; published 9 April 2015

Copyright (C 2015 by authors and Scientific Research Publishing Inc.

This work is licensed under the Creative Commons Attribution International License (CC BY).

http://creativecommons.org/licenses/by/4.0/

(c) (i) Open Access

\section{Abstract}

The selection of a starter is a complex process, involving different steps, like a preliminary characterization under laboratory conditions, the selection of the most promising strains, a lab validation and the final validation in a large-scale fermentation; the selection of a functional starter includes a further step, dealing with the assessment of the functional traits. This paper proposes a case study on how to use a step-by-step approach, based on some rapid protocols, to select promising starter cultures with probiotic abilities. Nine strains, isolated from a commercial preparation, were studied in relation to some enzymatic activities (slime and acetoin production, reduction of nitrates, proteolytic activity and hydrolysis of tributyrin), technological (acidification and growth at different temperatures, pHs and salt amounts) and probiotic traits (hydrophobicity, co-aggregation towards Salmonella sp. and Escherichia coli, survival at $\mathrm{pH} 2.5$ and in presence of bile salts, antibiotic resistance) and compared to some collection isolates. As a final step, a multivariate approach was used to select the most promising isolates. The isolates from the commercial preparation were able to perform the fermentation (e.g. acidification) at low temperatures with some interesting traits in terms of bioactivity towards $E$. coli $0157: \mathrm{H7}$, whilst some interesting probiotic traits in terms of hydrophobicity and survival in conditions that mimicked the gut were found for the collection isolates.

\section{Keywords}

Commercial Starter, Screening Protocols, Technological Performances, Functional Traits,

\footnotetext{
${ }^{*}$ Corresponding author.
}

How to cite this paper: Bevilacqua, A., Corbo, M.R., Speranza, B., Di Maggio, B., Gallo, M. and Sinigaglia, M. (2015) Functional Starter Cultures for Meat: A Case Study on Technological and Probiotic Characterization. Food and Nutrition Sciences, 6, 511-522. http://dx.doi.org/10.4236/fns.2015.65053 


\section{Multivariate Approach}

\section{Introduction}

The fermentation is one of the oldest forms of food processing and preservation in the world [1]; most traditional fermentations are conducted as uncontrolled and unpredictable spontaneous processes. Nowadays, some fermented products are produced on a large scale as a result of the application of modern technology, automation in production engineering, and biotechnology in the genetic manipulation of functional microorganisms [1]. The bacteria which have an important role and commonly found in fermented sausages are lactic acid bacteria (LAB), as they are used as starter cultures and promote meat fermentation [2]. A starter culture can be defined as a microbial preparation of large number of cells of at least one microorganism to be added to a raw material and produce a fermented food, conducting its fermentation kinetic and assuring food safety, shelf-life, technological and economic feasibility criteria [3]. Fermentation, conducted by LAB, has been shown to have not only preservative effects and the ability of aiding the modification of the physicochemical properties of different foods, but also the capability to provide significant impact on the nutritional quality and functional performances of the raw material [4]. Thus, they have a crucial role in the development of the nutritional, organoleptic, and microbiological quality, and health improvement of fermented products; in fact, the industrialization of food technology increased the economical importance of lactic acid bacteria, because this offers a possibility to explore the use of lactic acid bacteria as functional starter cultures for the manufacture of fermented foods [5]. Nevertheless, small-scale productions continue to use the traditional method of spontaneous fermentation without the addition of starter cultures, and let the "house-flora" to guide the fermentation [6]. Today, the main challenge in the design of starter cultures is to select strains able to improve food safety, and to preserve the typical sensory quality of traditional sausages [7]. The most commonly identified LAB species in traditional sausages are Lactobacillus sakei, Lb. curvatus and Lb. plantarum [7]. Lactobacillus strains isolated from fermented products are generally recognized as safe (GRAS, or QPS-qualified presumption of safety-in European Union).

Nowadays, there is a considerable interest towards probiotics for a variety of medical conditions, and millions of people around the world consume probiotics daily to maintain well-being [5]. Probiotics have a positive economic impact in Developing Countries, in which people suffer from frequent gastrointestinal infections [8]. Specific strains of Lactobacillus, Bifidobacterium and some Propionibacterium strains have been introduced as probiotics in food products due to their health-promoting effects [8]. The criteria for the selection of probiotics include the lack of pathogenicity, the tolerance to gastrointestinal conditions (acid and bile), the ability to adhere to gastrointestinal mucosa and the competitive exclusion of pathogens [8]. According to the FAO/WHO [9], one of the main selection criteria for potential probiotics strains is that they should adhere to intestinal mucosa and/ or epithelial cells. A new frontier goal for fermented meat is the use of functional starter cultures, i.e. starter cultures with an "added function"; some authors [6] [7] proposed the use of probiotic strains in sausages.

The selection of a starter is a complex process, involving different steps, like a preliminary characterization under laboratory conditions, the selection of the most promising strains, a lab validation and the final validation in a large-scale fermentation; the selection of a functional starter includes a further step, dealing with the assessment of the functional traits [10]. This paper proposes a case study on how to use a step-by-step approach, based on some rapid protocols, to select promising starter cultures with probiotic abilities; some strains isolated from a commercial starter were used as targets. The performances of the targets were compared with those experienced by some collection isolates.

\section{Materials and Methods}

\subsection{Strains}

Different strains were used throughout this study:

- Nine strains of lactic acid bacteria (labeled from st1 to st9), isolated from a commercial preparation and identified as $L b$. sakei, using the approach proposed by Bevilacqua et al. [11];

- Five strains purchased from a Public Collection (DSMZ, Deutsche Sammlung von Mikroorganismen und Zellkulturen’s collection, Braunschweig, Germany): Lactobacillus curvatus subsp. curvatus DSMZ 20019, 
Lb. plantarum DSMZ 1055, Lb. sakei DSMZ 15831, Leuconostoc carnosum DSMZ 5576, Pediococcus acidilactici DSMZ 20284.

- Lb. plantarum c19, a promising probiotic strain [11].

The strains were stored at $-20^{\circ} \mathrm{C}$ in MRS broth (Oxoid, Milan, Italy) added with $33 \%$ of sterile glycerol (J.T. Baker, Milan, Italy). Before each assay, the strains were grown under anaerobic conditions in MRS broth, incubated at $37^{\circ} \mathrm{C}$ for $24 \mathrm{~h}$.

\subsection{Preliminary Characterization and Metabolism}

The isolates from the commercial starter were characterized for the following traits:

a) Hetero-fermentative activity. It was carried out in MRS broth, supplemented with glucose (2\%) (JT Baker, Milan) and inoculated to $7 \mathrm{log} \mathrm{cfu} / \mathrm{ml}$. Gas production from glucose was determined using a Durham tube, after the incubation at $30^{\circ} \mathrm{C}$ for 7 days.

b) Hydrolysis of arginine. The ability to hydrolyze arginine with the production of ammonia and carbon dioxide was verified in the substrate of Abd-El-Malek ( $5 \mathrm{~g} / \mathrm{l}$ tryptone, $2.5 \mathrm{~g} / \mathrm{l}$ yeast extract, $0.5 \mathrm{~g} / \mathrm{l}$ glucose, $2 \mathrm{~g} / \mathrm{l}$ $\mathrm{K}_{2} \mathrm{HPO}_{4}, 3 \mathrm{~g} / \mathrm{l}$ arginine hydrochloride); the $\mathrm{pH}$ was adjusted to 7.0 . The broth was inoculated to $7 \mathrm{log} \mathrm{cfu} / \mathrm{ml}$ and incubated at $30^{\circ} \mathrm{C}$ for $96 \mathrm{~h}$. The presence of ammonia was detected qualitatively by the addition of one drop of Nessler's reagent (C. Erba, Milan, Italy).

c) Hydrolysis of aesculin. LAB were inoculated in MRS broth, buffered to pH 6.5 and supplemented with esculin (2 g/l) (Sigma-Aldrich) and ferric ammonium citrate (1 g/l) (C. Erba). The samples were then incubated at $30^{\circ} \mathrm{C}$ for $72 \mathrm{~h}$; colour turning to black denoted aesculin hydrolysis.

d) Production of acetoin. The production of acetoin was evaluated in the following broth: $5 \mathrm{~g} / \mathrm{l}$ bacteriological peptone, $5 \mathrm{~g} / \mathrm{l}$ glucose, $5 \mathrm{~g} / \mathrm{l} \mathrm{K} \mathrm{HPO}_{4}$. The broth was inoculated with LAB to $7 \mathrm{log} \mathrm{cfu} / \mathrm{ml}$ and incubated at $30^{\circ} \mathrm{C}$ for $4-7$ days. Colour turning to red after the addition of a drop of a $6 \%-\alpha$-naphthol solution (Sigma Aldrich) and a drop of $16 \%$ aqueous solution of $\mathrm{NaOH}$ highlighted the production of acetoin.

e) Reduction of nitrates. This test was performed in the Nitrate broth (8.6 g/l of peptone; $6.4 \mathrm{~g} / \mathrm{l} \mathrm{NaCl}, 1.5 \mathrm{~g} / \mathrm{l}$ $\mathrm{KNO}_{3}$ ); the $\mathrm{pH}$ was adjusted to $7.0-7.2$. The samples were inoculated to $7 \mathrm{log} \mathrm{cfu} / \mathrm{ml}$ and incubated at $30^{\circ} \mathrm{C}$ for 72 - $96 \mathrm{~h}$. The reduction of nitrate to nitrite was detected qualitatively by the addition of Griess Ilosvay's reagent (C. Erba).

f) Slime production. The production of slime was tested on MRS Agar (Oxoid) supplemented with 5\% sucrose (J. T. Baker). After streaking the strains onto the surface, the plates were incubated at $30^{\circ} \mathrm{C}$ for 7 days.

g) Lipolytic activity. This trait was assessed on PCA (Oxoid) supplemented with $2 \%$ of tributyrin (Sigma Aldrich). After inoculation, the plates were incubated at $30^{\circ} \mathrm{C}$ for 7 days; a clear halo around the colonies highlighted the hydrolysis of tributyrin.

h) Proteolytic activity. The strains were streaked onto the surface of PCA + 5\% Skim Milk Powder (Oxoid), incubated at $30^{\circ} \mathrm{C}$ for 7 days.

\subsection{Acidification}

The acidifying ability (i.e. the decrease of $\mathrm{pH}$ ) was assessed in MRS broth, inoculated to 6 log cfu/ml and incubated at $15^{\circ} \mathrm{C}, 25^{\circ} \mathrm{C}, 37^{\circ} \mathrm{C}$ and $44^{\circ} \mathrm{C}$; the pH was measured through a pH meter Crison 2001 (Crison Instruments, Barcelona, Spain).

\subsection{Effect of Temperature, NaCl, Nitrites and Nitrates on LAB Growth}

The assay was performed in MRS broth, added with $\mathrm{NaCl}(2 \%, 4 \%, 6.5 \%, 8 \%)$, nitrates $\left(\mathrm{NaNO}_{3}, 100\right.$ to 500 $\mathrm{ppm})$, nitrites $\left(\mathrm{NaNO}_{2}, 50\right.$ to $\left.300 \mathrm{ppm}\right)$. The samples were inoculated to $6 \mathrm{log} \mathrm{cfu} / \mathrm{ml}$ and incubated at $10^{\circ} \mathrm{C}$, $15^{\circ} \mathrm{C}, 25^{\circ} \mathrm{C}, 30^{\circ} \mathrm{C}, 37^{\circ} \mathrm{C}$ and $44^{\circ} \mathrm{C}$ up to 7 days. Aliquots of not modified MRS broth (pH 6.2), inoculated with the $\mathrm{LAB}$ and incubated at $30^{\circ} \mathrm{C}$, were used as positive controls. Microbial growth was evaluated as absorbance at $600 \mathrm{~nm}$, using a spectrophotometer Shimadzu UV-visible 1601 model 1642 (Shimadzu Europe Ltd., Duisburg, Germany). Data were modelled as Growth Index (GI) [12]:

$$
G I=\frac{A b s_{s}}{A b s_{c}} \times 100
$$

where $A b s_{s}$ is the absorbance of the samples at different $\mathrm{NaCl}$ concentrations, nitrates and nitrites concentrations, 
and temperature, and $A b s_{c}$ the absorbance of the positive control.

\subsection{Auto-Aggregation Assay}

Auto-aggregation was determined as described by Collado et al. [8]. Briefly, bacteria were grown for $18 \mathrm{~h}$ at $37^{\circ} \mathrm{C}$ in MRS broth (Oxoid); then cells were harvested by centrifugation, washed twice with phosphate-buffered saline (PBS $1 \mathrm{M}$; Sigma-Aldrich). The absorbance of the suspension $(600 \mathrm{~nm})$ was adjusted to 1.0; afterwards, $10 \mathrm{ml}$ of suspension were placed in sterile tubes and incubated at $25^{\circ} \mathrm{C}$, and the absorbance at $600 \mathrm{~nm}$ of the upper suspension was monitored after 2, 4, 6, 12, $24 \mathrm{~h}$. Auto-aggregation percentage was calculated with the following formula:

$$
A g=\left(1-\frac{A_{0}}{A_{t}}\right) \times 100
$$

where $A_{o}$ and $A_{t}$ are respectively the initial value and the absorbance at the time $t$.

\subsection{Hydrophobicity Assay}

The experiment was carried out according to the method described by Gong et al. [5] and Perricone et al. [13], with some modifications. Briefly, bacteria were grown at $37^{\circ} \mathrm{C}$ in MRS broth (Oxoid); then, cells were harvested by centrifugation and washed twice with PBS buffer $0.1 \mathrm{M}$. $9.5 \mathrm{ml}$ of cell suspension were added with $0.5 \mathrm{ml}$ of hexadecane or xylene (Sigma-Aldrich), thoroughly mixed for $30 \mathrm{~s}$ and left under static conditions for $10 \mathrm{~min}$. The ability of hexadecane to catch cells was evaluated through absorbance measurement at $600 \mathrm{~nm}$ after 60, 120, and $240 \mathrm{~min}$ and the data were modeled as Hydrophobic Index [13].

\subsection{Co-Aggregation Assay}

The co-aggregation test was performed as described by Collado et al. [8]. For this assay, the pathogenic strains were: Escherichia coli O157:H7 and Salmonella sp., belonging to the Culture Collection of the Laboratory of Predictive Microbiology, University of Foggia Briefly, bacteria suspensions were prepared as described for auto-aggregation analysis. Pathogens were grown in Nutrient broth (Oxoid) at their optimal conditions.

Equal volumes of cell suspension of each LAB (ca. $8 \mathrm{log} \mathrm{cfu} / \mathrm{ml})$ and pathogen strains (8 log cfu/ml) (1:1) were mixed for $20 \mathrm{~s}$ and then incubated at $25^{\circ} \mathrm{C}$ and the absorbance at $600 \mathrm{~nm}$ was evaluated immediately after the preparation and after 2, 4, 6, 12, $24 \mathrm{~h}$; two different controls were prepared: a sample containing only LAB and a sample with pathogens. Data were modeled as follows:

$$
C o-A g=\frac{\left(A_{x}+A_{y}\right)-A_{x+y}}{A_{x}+A_{y}} \times 100
$$

where $A_{x}$ and $A_{y}$ represent the absorbance of LAB and pathogens, respectively, and $A_{(x+y)}$ is the absorbance of the mix.

\subsection{Survival at $\mathrm{pH} 2.5$ and with $0.3 \%$ of Bile Salt Added}

Bacteria were grown at $37^{\circ} \mathrm{C}$ in MRS broth for $24 \mathrm{~h}$; cells were harvested by centrifugation and suspended in sterile distilled water. Aliquots of distilled water, inoculated with each LAB separately (7 - 8 log cfu/ml) acidified to $\mathrm{pH} 2.5$ or added with bile salt $0.3 \%(\mathrm{w} / \mathrm{v})$ (Oxoid) were stored at $37^{\circ} \mathrm{C}$. Cell viability was evaluated after 3 and $24 \mathrm{~h}$ through the pour plating (MRS agar incubated at $30^{\circ} \mathrm{C}$ for $2-4$ days under anaerobic conditions). Aliquots of distilled water inoculated with the strains were used as controls.

\subsection{Antibiotic-Resistance}

Antibiotic-resistance was carried out with the Kirby-Bauer method. The antibiotics used were: Erythromycin (78 mg), Gentamicin (40 mg), Chloramphenicol (60 mg), Tetracyclines (80 mg) Ampicillin (33 mg), Trimethoprim (5.2 mg), Ciprofloxacin (10 mg), Vancomycin (70 mg) (Neo Sensitabs ${ }^{\circledR}$, Taastrup, Denmark). 


\subsection{Statistical Analysis}

All the analyses were performed in duplicate over two different batches; the results were analyzed through oneway analysis of variance (one-way ANOVA), using the Tukey's test as the post-hoc comparison test $(\mathrm{P}<0.05)$. Moreover, the data from the technological and the probiotic characterization were used as input value to run a Principal Component Analysis. The statistical analyses were performed through the software Statistica for Windows (Statsoft, Tulsa, Okhla.).

\section{Results and Discussion}

\subsection{Technological Characterization}

The strains from the commercial preparation possessed an homofermentative metabolism and produced ammonium from arginine, whilst they did not hydrolyze the aesculin. Concerning the other enzymatic activities, they showed the production of slime (except for the strains st1 and st4), but they did not possess proteolytic and lipolytic metabolism (data not shown).

The study of the phenotypic and technological characteristics was a fundamental and critical step to define the profile of a meat starter. Heterofermentative LAB are not suitable for sausages production, because the formation of large amounts of carbon dioxide leads to holes of different sizes in the product; in addition, these LAB produce high acid acetic concentration that causes a pungent off-flavour [14]. Thus the homo-fermentative metabolism is a fundamental trait for a sausage starter and the isolates from the commercial preparation fulfill this requirement. Concerning the other enzymatic activities, the wild isolates were able to hydrolyze arginine and this trait was recovered in some other strains proposed as starter cultures for meat [15] [16]. The results for the proteolytic and lipolytic activities are in line with the results of many authors, as LAB do not possess significant proteolytic or lipolytic patterns, although a certain degree of peptidase and lipase activity was recovered in some strains isolated from meat products [6] [7].

Figure 1 shows the acidification of MRS after $24 \mathrm{~h}$; the strains from the commercial starter decreased the $\mathrm{pH}$ at $15^{\circ} \mathrm{C}$ by 0.7 and experienced a higher $\Delta \mathrm{pH}$ (ca. 1.5) at $25^{\circ} \mathrm{C}$, whilst the collection isolates did not decrease the $\mathrm{pH}$ at $15^{\circ} \mathrm{C}$.

Concerning the effect of the temperature (Figure 2), as expected after $24 \mathrm{~h}$ none of the studied strains (both the isolates from the commercial preparation and the collection microorganisms) showed a significant growth at $10^{\circ} \mathrm{C}$ and $15^{\circ} \mathrm{C}$, whereas at $44^{\circ} \mathrm{C}$ the GI was strongly strain-dependent, being ca. $100 \%$ for the collections strains and for 3 isolates from the commercial starter (st3, st6 and st8) and ca. $0 \%-5 \%$ for the isolates st1, st2, st 4 , st5, st7 and st9. After $48 \mathrm{~h}$ (Figure 2(b)), we found a significant increase of the GI at $15^{\circ} \mathrm{C}$ for all the isolates from the commercial starter and for some collection strains (Ln. carnosum, P. acidilactici, Lb. plantarum

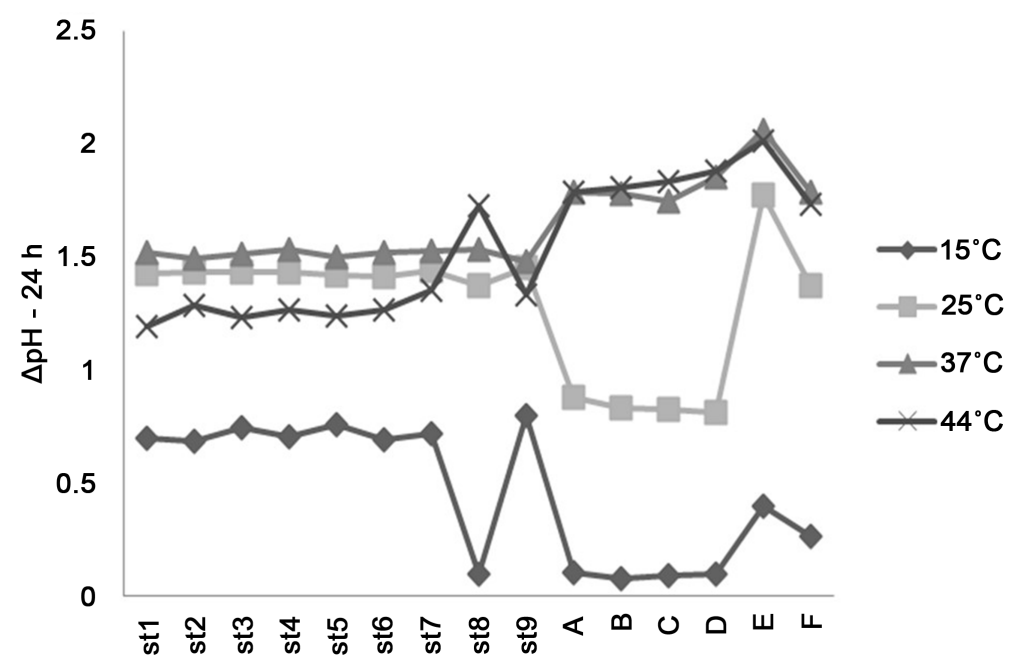

Figure 1. Acidification of the isolates from the starter and the collection strains in MRS broth, stored at $15^{\circ} \mathrm{C}, 25^{\circ} \mathrm{C}, 37^{\circ} \mathrm{C}$ and $44^{\circ} \mathrm{C}$ for $24 \mathrm{~h}$. Data are the mean value. A, Ln. carnosum; $\mathrm{B}, P$. acidilactici; C, Lb. curvatus; D, Lb. plantarum DSMZ 1055; E, Lb. plantarum C19; F, Lb. sakei. 


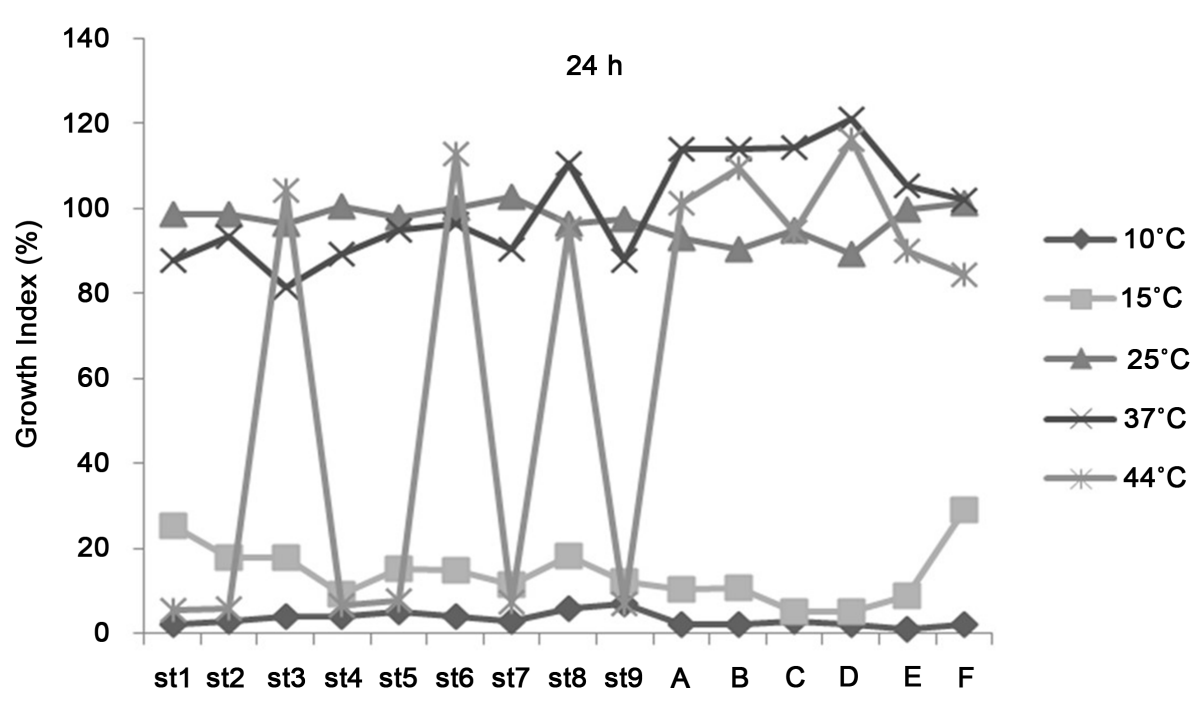

(a)

$48 \mathrm{~h}$

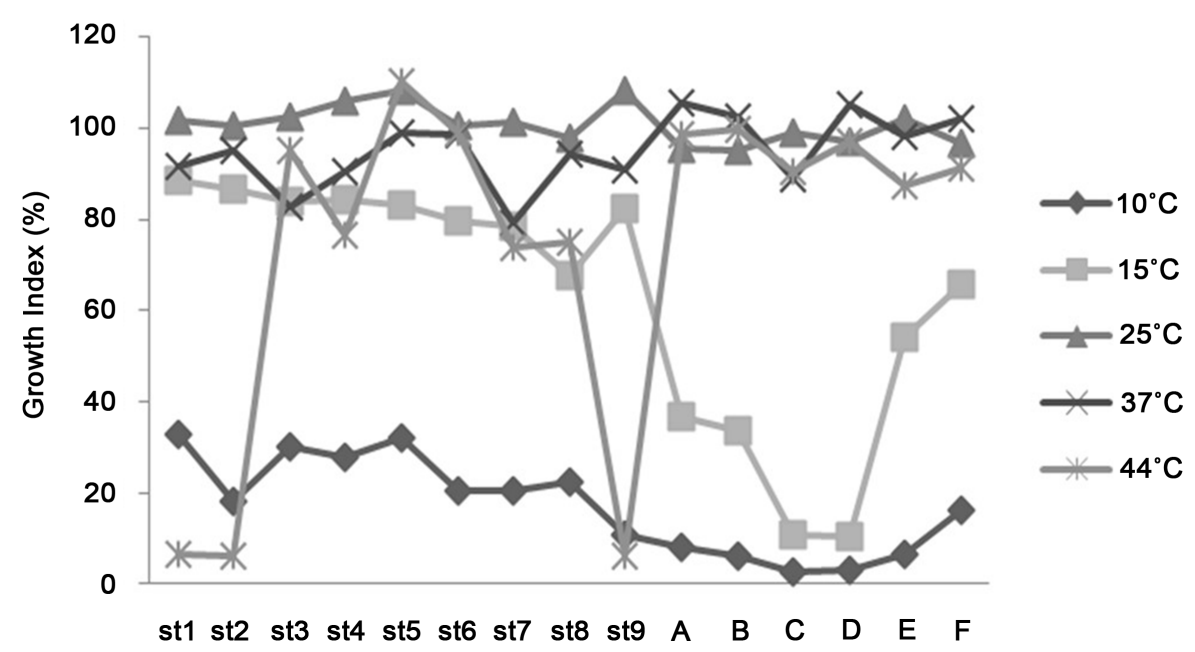

(b)

Figure 2. Growth Index (\%) of the strains in MRS broth incubated at different temperatures after 24 (a) and 48 h (b). Data are the mean value. A, Ln. carnosum; B, P. acidilactici; C, Lb. curvatus; D, Lb. plantarum DSMZ 1055; E, Lb. plantarum C19; F, Lb. sakei.

c19 and $L b$. sakei); moreover, the isolates st1, st3, st4, and st5 showed a GI $>25 \%$ at $10^{\circ} \mathrm{C}$ (ca. $27 \%-32 \%$ ), which pointed out a moderate growth and only a partial inhibition due to the low temperature [17]. After $48 \mathrm{~h}$ there was also a significant increase of the GI at $44^{\circ} \mathrm{C}$ for the isolates st 4 , st5, and st9.

Figure 3 reports the effect of salt; the isolates st 1 to st 9 were moderately affected by $4 \% \mathrm{NaCl}$, with a GI of $45 \%$ - $66 \%$, and were strongly inhibited by higher amounts; after $48 \mathrm{~h}$ there was a significant increase of GI in the broth containing $6.5 \%$ of $\mathrm{NaCl}$ up to $50 \%-60 \%$ (data not shown).

The effect of temperature on the isolates from the commercial preparation was in line with the results of many authors. For example, Papamonoli et al. [15] and Santos et al. [18] [19] reported that ca. 80\% - 90\% of LAB strains from meat were able to grow at $15^{\circ} \mathrm{C}$, whilst the ability to grow at higher temperatures was found only in a half of meat microbiota [16]. Concerning the effect of salt, our strains showed a significant deviation from the expected outcome, as they appeared more sensitive than the wild microbiota of meat able to grow in presence of $6.5 \%-10 \% \mathrm{NaCl}[15]$. 


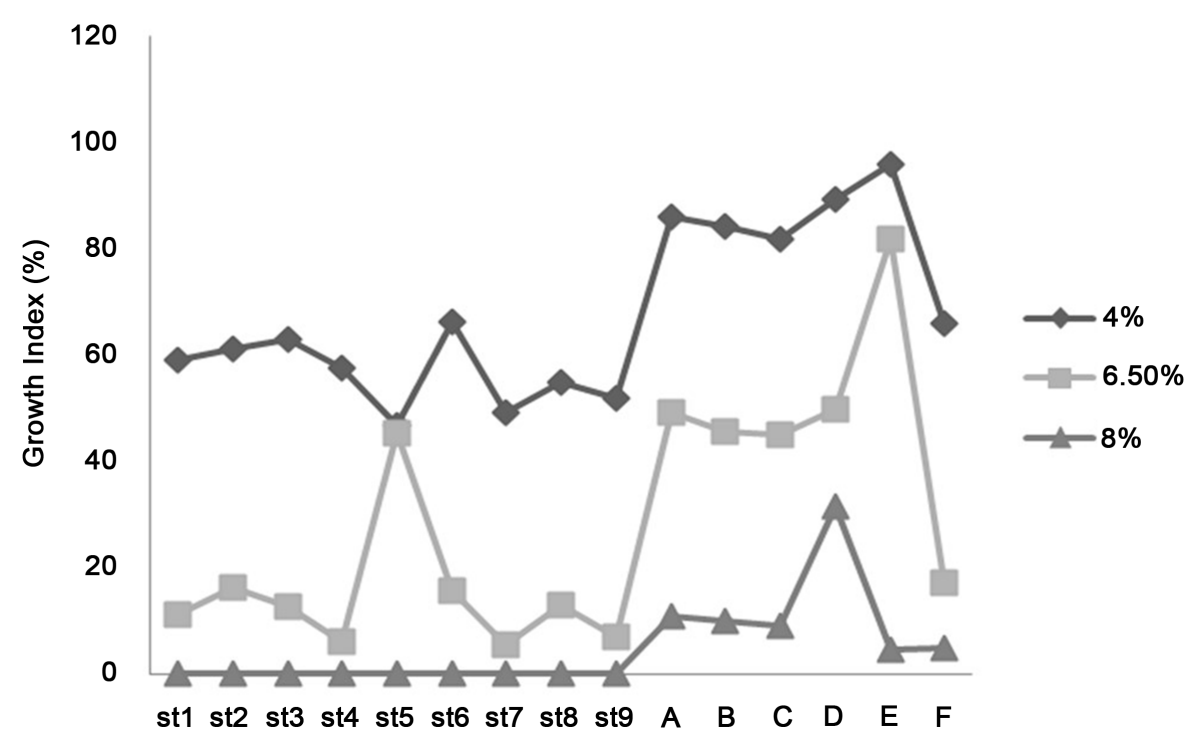

Figure 3. Growth Index (\%) of the strains in MRS broth $+\mathrm{NaCl}$ after $24 \mathrm{~h}$. Data are the mean value. A, Ln. carnosum; B, P. acidilactici; C, Lb. curvatus; D, Lb. plantarum DSMZ 1055; E, Lb. plantarum C19; F, Lb. sakei.

\subsection{Functional Characterization}

The functional characterization was based upon the assessment of some classical traits (survival at $\mathrm{pH} 2.5$ and with bile salts added, antibiotic resistance), as well as on some screening protocols for the evaluation of the ability to adhere to the mucosa of the gut (hydrophobicity, auto-aggregation) and the antimicrobial activity towards food-borne pathogens (co-aggregation).

Based on the Hydrophobic Index (Figure 4), the different targets could be divided into different groups as follows:

a) Strains with a hydrophilic trend (low Hydrophobic Index, HI) or with a variable HI: st2, st6, st8, st9, $L b$. curvatus;

b) Isolates with a moderate $\mathrm{HI}$ (ca. 16\%), st1, st3, st4 and st5;

c) Collection strains with a high HI, Ln. carnosum, P. acidilactici, and both the strains of Lb. plantarum;

d) $L b$. sakei showed an intermediate trend between the isolates from the commercial preparation and the collection strains.

Another interesting trait is the auto-aggregation (Table 1) (Ag); this parameter increased over the time and after $24 \mathrm{~h}$ all the targets showed a $\mathrm{Ag}>32 \%$, with the maximum values recovered for the isolates st9 and $\mathrm{Ln}$. carnosum.

The targets were able to exert a significant bioactivity towards Salmonella sp. after $12 \mathrm{~h}$, with a co-aggregation index (Co-Ag) ranging from $21.40 \%$ (isolate st2) to $42.99 \%$ ( $L$ b. curvatus); the statistical analysis (one-way ANOVA) highlighted a continuous distribution rather than a discrete grouping of the strains, being the less active the strain st2 and the most effective the collection strain of $L b$. curvatus, whilst all the other strains belonged to an intermediate class of bioactivity (Co-Ag of $24.56 \%$ - 38.04\%) (Table 2). On the other hand, the microorganisms experienced lower Co-Ag towards E. coli, with an index up to $17 \%$ (data not shown).

Concerning the effect of bile salt, the targets experienced a low reduction in cell count (up to $1.76 \mathrm{log} \mathrm{cfu} / \mathrm{ml}$ for the isolate st6), whilst the acidic $\mathrm{pH}$ exerted a stronger effect, being the strains st6 and $L b$. curvatus the most sensitive ones, as they were respectively reduced by 5.79 and $3.50 \mathrm{log} \mathrm{cfu} / \mathrm{ml}$, against the viable count of the other strains decreasing by 1 - 2 log cfu/ml (Figure 5).

The final step of the probiotic characterization was the evaluation of the antibiotic-resistance. All the strains were resistant to vancomycin, ciprofloxacin and trimethoprim, while for the other antibiotics the bacterial growth was inhibited, with the exception of the isolates st3 and st1, because they were resistant to Gentamicyn and Tetracyclines, respectively (data not shown).

Auto-aggregation and hydrophobicity play an important role in the adhesion to gut mucosa [5]. Bacterial 


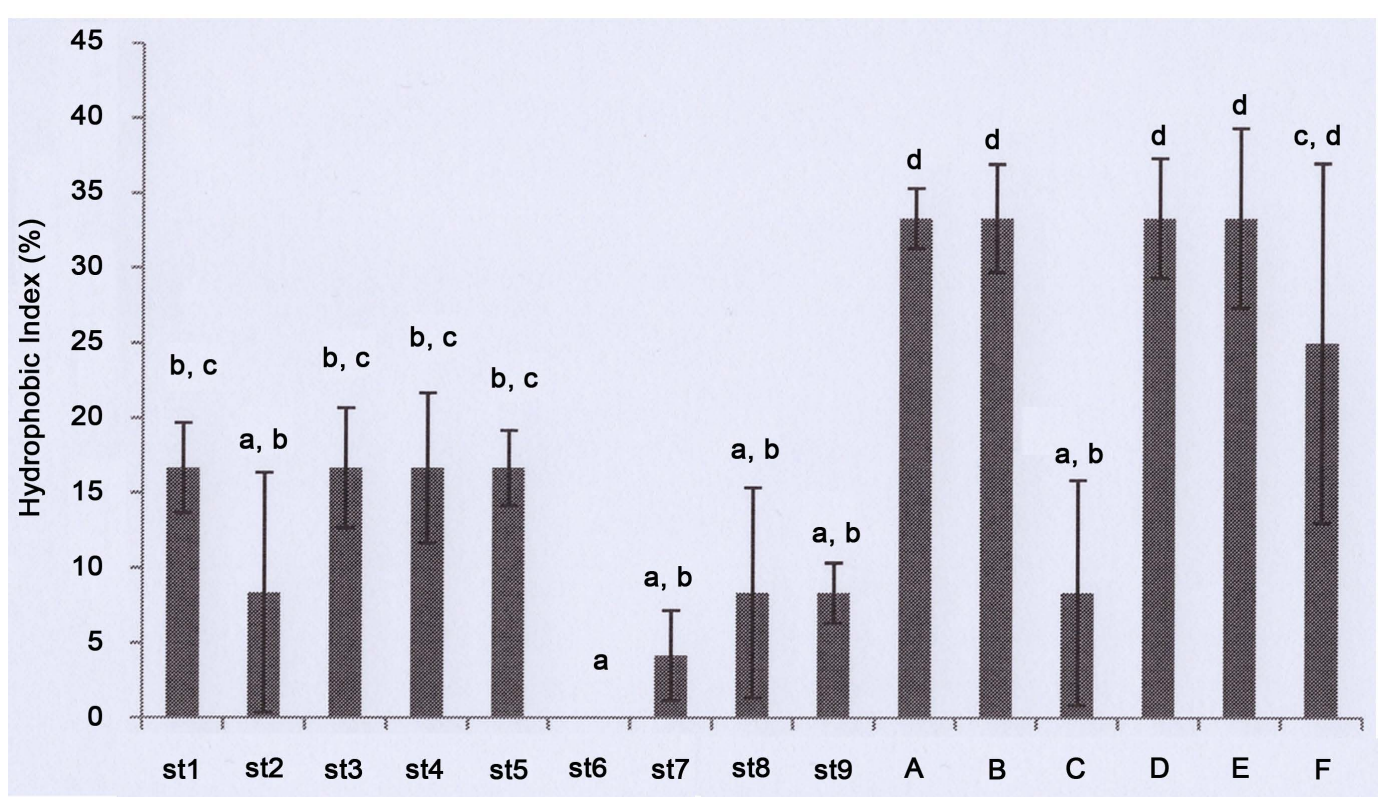

Figure 4. Hydrophobic Index (\%) of the strains. Mean value \pm standard deviation. The small letters indicate the significant differences (one-way ANOVA and Tukey’s test). A, Ln. carnosum; B, P. acidilactici; C, Lb. curvatus; D, Lb. plantarum DSMZ 1055; E, Lb. plantarum C19; F, Lb. sakei.

Table 1. Auto-aggregation of the targets after $24 \mathrm{~h}$; mean values \pm standard deviation. Data were analyzed through one-way ANOVA, using the approach of the homogeneous group.

\begin{tabular}{|c|c|c|c|}
\hline \multirow{2}{*}{ Strains } & \multirow{2}{*}{ Auto-aggregation (\%) } & \multicolumn{2}{|c|}{ Homogeneous groups } \\
\hline & & $\mathbf{I}$ & II \\
\hline St1 & $31.78 \pm 4.00$ & & \\
\hline St7 & $32.21 \pm 3.93$ & & \\
\hline St6 & $39.93 \pm 8.04$ & & \\
\hline Lb. curvatus subsp. curvatus DSMZ 20019 & $41.91 \pm 2.55$ & & \\
\hline P. acidilactici DSMZ 20284 & $42.44 \pm 10.97$ & & \\
\hline Lb. sakei DSMZ 15831 & $48.73 \pm 2.65$ & & \\
\hline St5 & $51.34 \pm 5.21$ & & \\
\hline St3 & $51.83 \pm 0.08$ & & \\
\hline St2 & $52.07 \pm 0.11$ & & \\
\hline Lb. plantarum DSMZ 1055 & $53.42 \pm 4.53$ & & \\
\hline St4 & $56.35 \pm 0.15$ & & \\
\hline St8 & $56.36 \pm 1.09$ & & \\
\hline Lb. plantarum c19 & $56.51 \pm 8.26$ & & \\
\hline St9 & $59.75 \pm 4.74$ & & \\
\hline Ln. carnosum DSMZ 5576 & $60.97 \pm 4.19$ & & \\
\hline
\end{tabular}




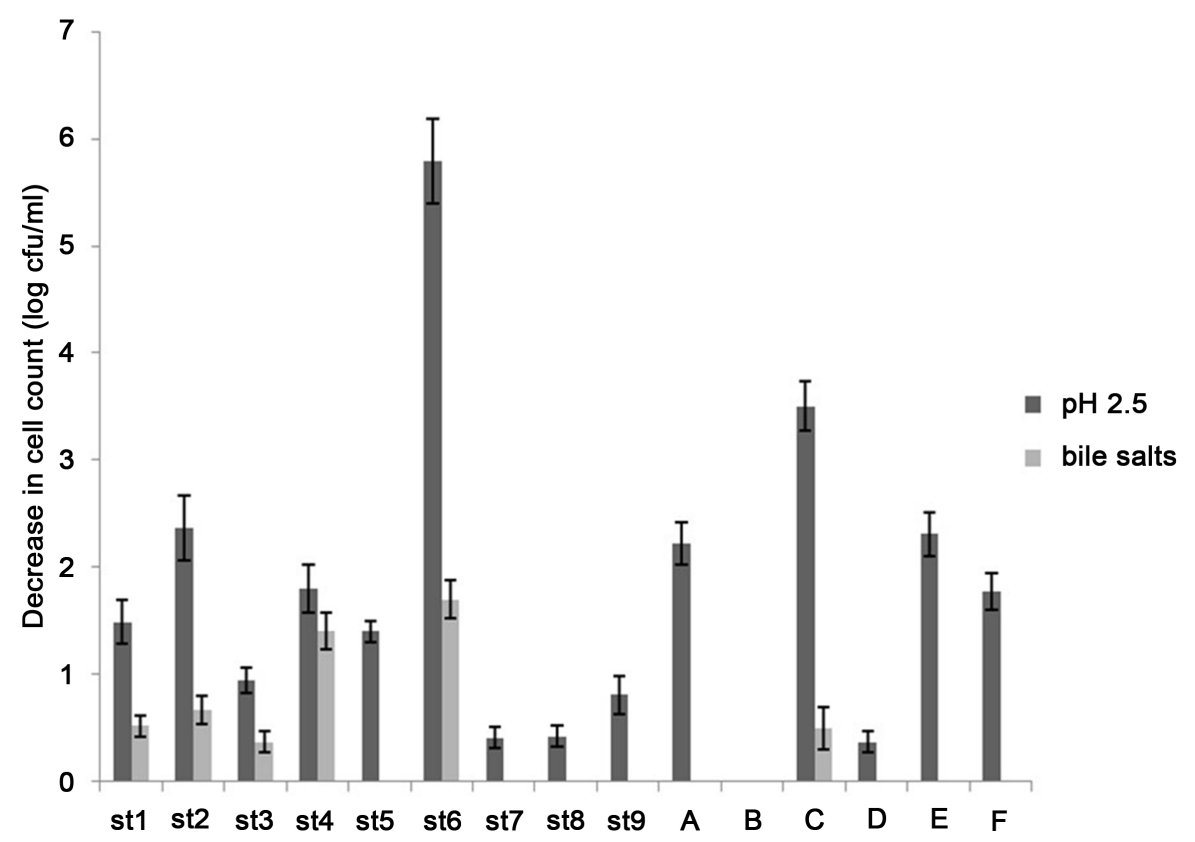

Figure 5. Decrease in cell count after $3 \mathrm{~h}$ of incubation in distilled water acidified to $\mathrm{pH} 2.5$ or added with bile salt. Mean values \pm standard deviation.

Table 2. Co-aggregation of LAB with Salmonella sp.: mean values \pm standard deviation. Data were analyzed through oneway ANOVA, using the approach of the homogeneous group.

\begin{tabular}{ccc}
\hline LAB/Salmonella (12 h) & Co-aggregation (\%) & Homogeneous groups \\
\cline { 2 - 2 } ST2 & $21.40 \pm 8.25$ & I \\
Lb. plantarum c19 & $24.56 \pm 0.92$ \\
Lb. sakei DSMZ 15831 & $25.60 \pm 11.30$ \\
ST5 & $32.23 \pm 1.27$ \\
ST3 & $33.77 \pm 6.18$ \\
Ln. carnosum DSMZ 5576 & $33.80 \pm 0.59$ \\
ST6 & $34.29 \pm 1.74$ \\
ST9 & $34.81 \pm 1.16$ \\
ST1 & $35.12 \pm 1.23$ \\
Lb. plantarum DSMZ 1055 & $35.67 \pm 6.56$ \\
ST4 & $36.56 \pm 3.99$ \\
ST7 & $36.92 \pm 0.32$ \\
ST8 & $37.19 \pm 1.93$ \\
Lb. curvatus subsp. curvatus DSMZ 20019 & $38.04 \pm 3.50$ \\
\hline
\end{tabular}

adhesion to intestinal epithelial cells depends by composition and structure of the membranes and force of interaction [8] [20]; moreover, it is a multistep process, connected to the hydrophobic properties of cell surfaces. It has been reported that the most hydrophobic a microorganism behaves the most it adheres to gut [13].

Another desired trait for a probiotic is the ability to compete with pathogens in the intestine; we studied this phenomenon through the co-aggregation. It is an indirect index connected with the ability to catch pathogens, thus avoiding their adhesion to the mucosa [8].

A final highlight on the implication of antibiotic resistance. The antibiotic resistance per se is not a safety issue, but it could pose a strong threat for the health when the genetic determinants are carried out by mobile ele- 
ments [21]. Therefore EFSA (European Food Safety Authority) requires for a food-grade microorganism to be sensitive to the antibiotics or at least to possess chromosomal determinants for the resistance [22].

For this last trait, the profile of the isolates from the commercial starter was in line with the literature [7] [22], with two exceptions to this statement: the isolates st1 and st4.

\subsection{Multivariate Analysis}

The data from the technological characterization, as well as the probiotic traits of the targets, were used as input data to run a multivariate analysis; the targets could be divided into 2 main groups, the first one comprising the collection strains and the second one the isolates from the commercial starter; however, there were some exceptions to this generalized statement, as $L b$. sakei showed an intermediate trend between the collection and the wild isolates and $L b$. plantarum c19 experienced a trend different from all the other collection strains (Figure 6(a) and Figure 6(b)).

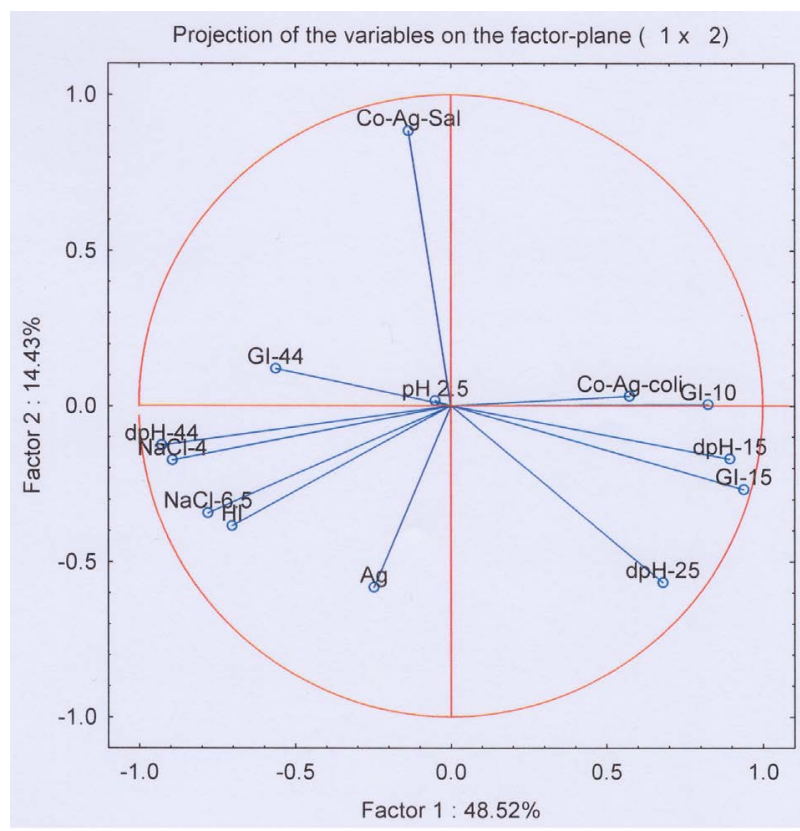

(a)

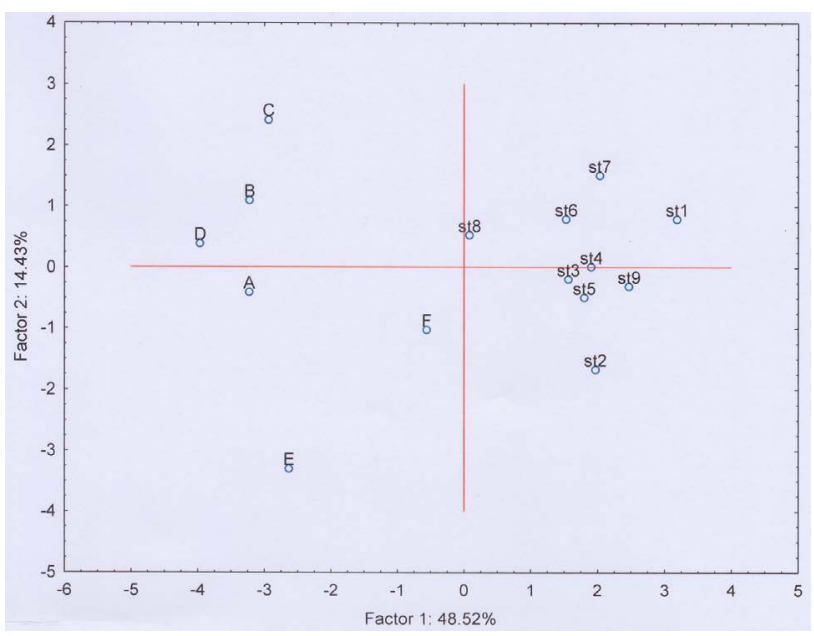

(b)

Figure 6. Principal component analysis (PCA); the results of technological and probiotic characterization were used as input data. (a) Projection of the variables; (b) Multivariate isolates. 
The isolates from the starter showed better performances at lower temperatures $\left(10^{\circ} \mathrm{C}\right.$ and $\left.15^{\circ} \mathrm{C}\right)$ in terms of growth and acidification of a lab medium, with some interesting values of co-aggregation towards $E$. coli O157:H7; on the other hand the collection isolates showed interesting functional traits and better performances in presence of salt and at higher temperatures.

\section{Conclusions}

This paper shows a case study on a possible flow-sheet with some rapid protocols to select promising starter cultures, with probiotic abilities, intended for meat. The selection relies upon some traits, i.e.:

a) The qualitative assessment of the enzymatic activities;

b) The evaluation of the performances (acidification) and growth by using the Growth Index approach;

c) A screening on the probiotic properties, using some classical traits (antibiotic resistance, resistance at low $\mathrm{pH}$ and in presence of bile salts) and some indirect indices connected with the adhesion to the mucosa (aggregation and hydrophobicity) and the bioactivity towards pathogens (co-aggregation);

d) The selection of the most promising strains or the evaluation of the global performance of the strains through a multivariate approach.

Concerning the performances of the isolates from the commercial starter, they experienced the classical ability of the starter culture intended for meat and were able to perform the fermentation at low temperatures, with some interesting traits in terms of bioactivity towards E. coli O157:H7.

\section{Acknowledgements}

This research was supported by the Italian Ministry of Education, University and Research (MIUR) through the project PON-01-1409 "Process and product innovations aimed at increasing food safety and at diversifying pork-based products” (SAFEMEAT).

\section{References}

[1] Saloomeh, M.J., Line, L.P. and Lene, J. (2010) Beneficial Effects of Probiotic and Food Borne Yeasts on Human Health. Nutrients, 2, 449-473. http://dx.doi.org/10.3390/nu2040449

[2] El-Malti, J. and Amarouch, H. (2009) Microbiological and Physicochemical Characterization of the Natural Fermented Camel Meat Sausage. African Journal of Biotechnology, 8, 4199-4206.

[3] Champagne, C.P. and Møllgaard, H. (2008) Production of Probiotic Cultures and Their Addition in Fermented Foods. In: Farnworth, E.R., Ed., Handbook of Fermented Functional Foods, Taylor \& Francis Group, Boca Raton, 513-532.

[4] Kos, B., Suskovic, J., Vukovic, S., Simpraga, M., Frece, J. and Matosic, S. (2003) Adhesion and Aggregation Ability of Probiotic Strain Lactobacillus acidophilus M92. Journal of Applied Microbiology, 94, 981-987. http://dx.doi.org/10.1046/j.1365-2672.2003.01915.x

[5] Gong, X., Yu, H., Chen, J. and Han, B. (2012) Cell Surface Properties of Lactobacillus salivarus under Osmotic Stress. European Food Research and Technology, 234, 671-678. http://dx.doi.org/10.1007/s00217-012-1677-z

[6] Leroy, F., Verluyten, J. and De Vuyst, L. (2006) Functional Meat Starter Cultures for Improved Sausage Fermentation. International Journal of Food Microbiology, 106, 270-285. http://dx.doi.org/10.1016/j.ijfoodmicro.2005.06.027

[7] Babić, I., Markov, K., Kovačević, D., Trontel, A., Slavica, A., Đugum, J., Čvek, D. and Svetec, I.K. (2011) Identification and Characterization of Potential Autochthonous Starter Cultures from a Croatian "Brand" Product "Slavonski Kulen”. Meat Science, 88, 517-524. http://dx.doi.org/10.1016/j.meatsci.2011.02.003

[8] Collado, M.C., Meriluoto, J. and Salminen, S. (2008) Adhesion and Aggregation Properties of Probiotic and Pathogen Strains. European Food Research and Technology, 226, 1065-1073. http://dx.doi.org/10.1007/s00217-007-0632-x

[9] FAO/WHO (2002) Guidelines for the Evaluation of Probiotics in Food. Food and Agriculture Organization of the United Nations and World Health Organization Working Group Report. http://www.who.int/foodsafety/publications/fs_management/probiotics2/en/

[10] Bevilacqua, A., Corbo, M.R. and Sinigaglia, M. (2012) Selection of Yeasts as Starter Cultures for Table Olives: A Stepby-Step Procedure. Frontiers in Food Microbiology, 3, Article 194. http://dx.doi.org/10.3389/fmicb.2012.00194

[11] Bevilacqua, A., Altieri, C., Corbo, M.R., Sinigaglia, M. and Ouoba, L.I.I. (2010) Characterization of Lactic Acid Bacteria Isolated from Italian Bella Di Cerignola Table Olives: Selection of Potential Multifunctional Starter Cultures. Journal of Food Science, 75, M536-M544. http://dx.doi.org/10.1111/j.1750-3841.2010.01793.x

[12] Bevilacqua, A., Perricone, M., Cannarsi, M., Corbo, M.R. and Sinigaglia, M. (2009) Technological and Spoiling Cha- 
racteristics of the Yeast Microflora Isolated from Bella Di Cerignola Table Olives. International Journal of Food Science \& Technology, 44, 2198-2207. http://dx.doi.org/10.1111/j.1365-2621.2009.02060.x

[13] Perricone, M., Bevilacqua, A., Corbo, M.R. and Sinigaglia, M. (2014) Technological Characterization and Probiotic Traits of Yeasts Isolated from Altamura Sourdough to Select Promising Microorganisms as Functional Starter Cultures for Cereal-Based Products. Food Microbiology, 38, 26-35. http://dx.doi.org/10.1016/j.fm.2013.08.006

[14] Ammor, M.S. and Mayo, B. (2007) Selection Criteria for Lactic Acid Bacteria to Be Used as Functional Starter Cultures in Dry Sausage Production: An Update. Meat Science, 76, 138-146. http://dx.doi.org/10.1016/j.meatsci.2006.10.022

[15] Papamanoli, E., Tzanetakis, N., Litopoulou-Tzanetaki, E. and Kotzekidou, P. (2003) Characterization of Lactic Acid Bacteria Isolated from a Greek Dry Fermented Sausage in Respect of Their Technological and Probiotic Properties. Meat Science, 65, 859-867. http://dx.doi.org/10.1016/S0309-1740(02)00292-9

[16] Benito, M.J., Martìn, A., Aranda, E., Pérez-Nevado, F., Ruiz-Moyano, S. and Còrdoba, M.G. (2007) Characterization and Selection of Autochthonous Lactic Acid Bacteria Isolated from Traditional Iberian Dry-Fermented Salchichón and Chorizo Sausages. Food Microbiology and Safety, 72, M193-M201.

[17] Bevilacqua, A., Beneduce, L., Sinigaglia, M. and Corbo, M.R. (2013) Selection of Yeasts as Starter Cultures for Table Olives. Journal of Food Science, 78, M742-M751. http://dx.doi.org/10.1111/1750-3841.12117

[18] Santos, E.M., González-Fernández, C., Jaime, I. and Rovira, J. (1998) Comparative Study of Lactic Acid Bacteria House Flora Isolated in Different Varieties of Chorizo. International Journal of Food Microbiology, 39, 123-128. http://dx.doi.org/10.1016/S0168-1605(97)00128-1

[19] Santos, E.M., González-Fernández, C., Jaime, I. and Rovira, J. (1997) Identification and Characterization of Lactic Acid Bacteria Isolated from Traditional Chorizo Elaborated in Castilla-Leon. Food Science and Technology International, 3, 21-29. http://dx.doi.org/10.1177/108201329700300103

[20] Wang, L.Q., Meng, X.C., Zhang, B.R., Wang, Y. and Shang, Y.L. (2010) Influence of Cell Surface Properties on Adhesion Ability of Bifidobacteria. World Journal of Microbiology \& Biotechnology, 26, 1999-2007. http://dx.doi.org/10.1007/s11274-010-0384-9

[21] Gueimonde, M., Sánchez, B., de los Reyes-Gavilán, C.G. and Margolles, A. (2013) Antibiotic Resistance in Probiotic Bacteria. Frontiers in Microbiology, 4, 202. http://dx.doi.org/10.3389/fmicb.2013.00202

[22] Bevilacqua, A., Campaniello, D., Speranza, B., Sinigaglia, M. and Corbo, M.R. (2014) Selection of Promising Probiotic Strains for Foods: Proposal for a Possible Flow-Chart with a Special Focus on the Dark Side of Probiotics. In: Roma, A., Ed., Probiotics in Health and Disease, Nova Publishers, Washington DC, 1-22. 